\title{
Fuzzy Logic Controller for Three Phase PWM AC-DC Converter
}

\author{
Mian Muhammad Kamal ${ }^{1, a}$, Husan Ali ${ }^{2, b}$ and Bakht Muhammad Khan ${ }^{3, c}$ \\ ${ }^{1,2,3}$ Northwestern Polytechnical University, Xi'an, 710072, P.R.China \\ amiankamal@mail.nwpu.edu.cn, ${ }^{\mathrm{b}}$ husan@mail.nwpu.edu.cn, ${ }^{\mathrm{c} e n g i n e e r b a k h t @ y a h o o . c o m ~}$
}

Keywords: PWM converter, Fuzzy logic controller, Power factor, Total harmonic distortion, Voltage regulation.

Abstract. This paper discusses control strategy for the voltage regulation of a three phase pulse width modulation (PWM) AC-DC converter. A fuzzy logic controller (FLC) is employed in the outer voltage loop. Fuzzy logic controllers are preferred over the conventional proportional integral (PI) controllers because they are based on linguistic description and do not require a prior mathematical model of the system. The objective of the presented control system is to regulate the output DC voltage during both transient and steady state period. Also the line currents drawn from the grid should be sinusoidal and in phase with respective phase voltages to achieve a low total harmonic distortion (THD) and unity power factor. PI and FLC based control systems are implemented for three phase PWM AC-DC converter in MATLAB/Simulink and dynamic performance of the system is tested. The results demonstrate that compared to the conventional PI, the FLC based system is more robust and has a much better dynamic response. The low value of THD and sinusoidal current response ensures the system avoids polluting the utility grid.

\section{Introduction}

The commonly employed three phase AC-DC converters in industrial applications and consumer products are based upon a diode bridge circuit and a large storage capacitor. Although this system has the advantage of being robust and low cost, its drawbacks are unidirectional power flow, low power factor, and high total harmonic distortion (THD) for input line current. To overcome these drawbacks pulse width modulation (PWM) AC-DC converters are used, which effectively regulate the output DC voltage and have a low value of THD. The PWM AC-DC converters have the capability of bi-directional power flow, unit power factor, low THD and a regulated DC voltage at the output [1-3]. Fig. 1 shows the topology of three phase PWM AC-DC converter. The converter is supplied by a three phase voltage source connected via $L$-filter. 


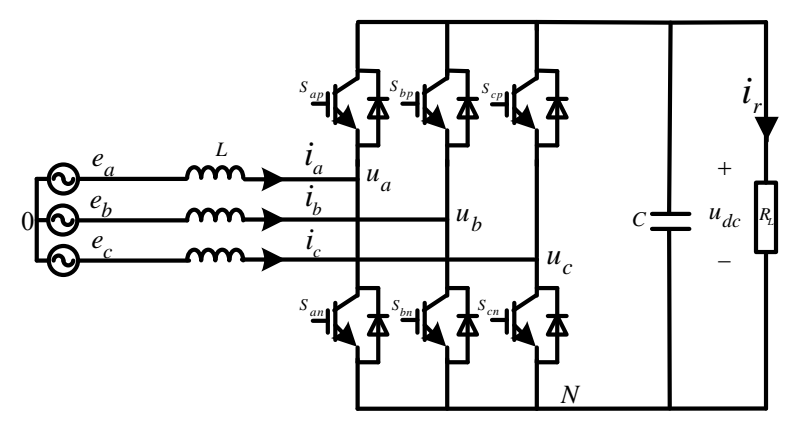

Fig. 1. Three-phase PWM AC-DC converter

To regulate the operation of three phase PWM AC-DC converters, proportional integral (PI) and proportional integral derivative (PID) controllers are commonly used. Although the conventional PI and PID controllers are relatively easy to implement, however their design is based upon an explicit mathematical model of the system and they also lack in intelligence.

This leads us to adaptive controllers, i.e. fuzzy logic, neural network, neuro fuzzy etc. These controllers do not require mathematical model of the system prior to the control system design [4-5] and also have the ability to handle nonlinearity of the system. Among these fuzzy logic based controller is much robust and least sensitive to disturbances [6].

In this study, fuzzy logic controller (FLC) is used to regulate the output voltage of three phase AC-DC converter. Fig. 2 shows the control system developed for three phase PWM converter which is composed of two inner current loops and an outer DC voltage loop. The fuzzy logic controller is employed in the outer voltage loop for dc-bus voltage regulation. The FLC based voltage controller generates reference current command fed to inner current loop. The inner loops employ PI based current controller.

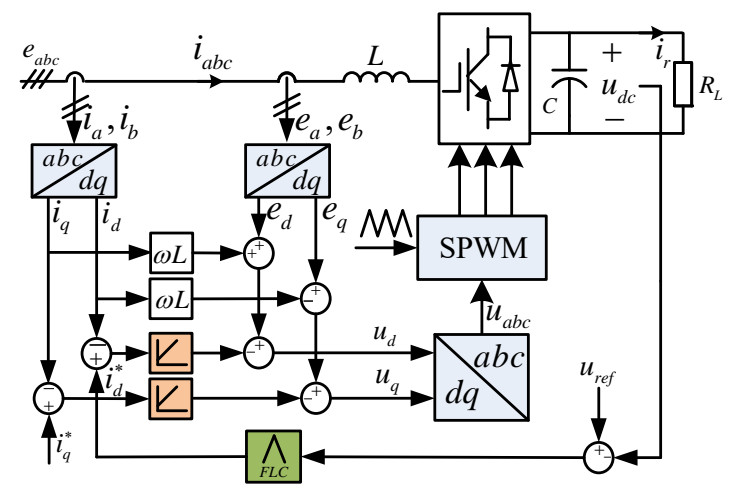

Fig. 2. Fuzzy logic control scheme implementation for three phase converter

\section{Fuzzy Logic Controller}

The basic architecture of a FLC is shown in Fig. 3. Three main blocks of the FLC are fuzzifier, inference engine and the defuzzifier.

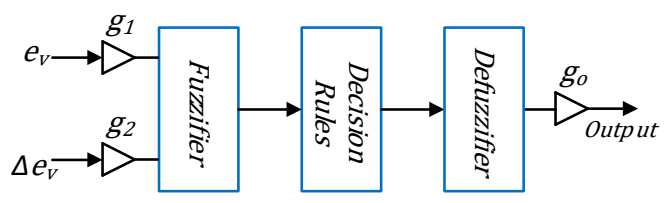

Fig. 3. Fuzzy logic controller block diagram. 
The numerical variables, error $\left(e_{v}\right)$ and change in error $\left(\Delta e_{v}\right)$ are the two inputs applied to the fuzzifier block of the FLC. Fuzzifier converts measured quantities into fuzzy sets which are then given as input to the inference engine. In order to convert the applied numerical variables into linguistic variables, five fuzzy sets are used from negative big (NB) to positive big (PB). Among several membership functions to define fuzzy sets, few commonly used are triangular, guassian and trapezoidal etc. In this work, triangular membership functions are used as they are more effective to achieve a better transient response [7].

The input to FLC is the difference of output voltage and reference voltage $\left(V_{\text {ref }}-V_{o}\right)$, which is normalized so the universe of discourse is selected to be between -1 and 1 . The triangular membership functions used are labelled as NB, NS, ZE, PS and PB for "Negative Big", "Negative Small", "Zero", "Positive Small" and "Positive Big" respectively. The x-axis represents the error and change in error, while the y-axis shows the degree of membership $\mu$.

The second block i.e. inference engine is based upon a set of if-then rules. The set of these rules enables FLC to take intelligent decisions [8]. In this study the inputs and output are related by a set of 25 rules which are shown in Table 1.

Table 1 Fuzzy Logic Rule Set

\begin{tabular}{c|ccccc}
$\Delta e_{v} / e_{v}$ & $\mathbf{N B}$ & $\mathbf{N S}$ & $\mathbf{Z E}$ & $\mathbf{P S}$ & $\mathbf{P B}$ \\
\hline $\mathbf{N B}$ & NB & NS & NS & ZE & ZE \\
$\mathbf{N S}$ & NB & NS & NS & ZE & PS \\
$\mathbf{Z E}$ & NS & NS & ZE & PS & PS \\
PS & NS & ZE & PS & PS & PB \\
PB & ZE & ZE & PS & PS & PB
\end{tabular}

Finally the defuzzifier block converts the control output generated by the inference engine into the numerical variable.

\section{Results and Discussion}

The PI and FLC based PWM AC-DC converter system is simulated in MATLAB/Simulink software. The parameters used for the simulated system are given in Table 2.

Table 2 Simulation Parameters

\begin{tabular}{ll}
\hline \hline Parameter & Value \\
\hline Input AC voltage $\left(V_{r m s}\right)$ & $115[\mathrm{~V}]$ \\
Source frequency $\left(V_{r m s}\right)$ & $400[\mathrm{~Hz}]$ \\
Filter inductor $(L)$ & $0.325[\mathrm{mH}]$ \\
Output filter capacitor $(C)$ & $3300[\mu \mathrm{F}]$ \\
Load voltage $\left(V_{o}\right)$ & $400[\mathrm{~V}]$ \\
Active Power $(P)$ & $15 \mathrm{k}[\mathrm{W}]$
\end{tabular}

Both the control systems are put under test by applying a resistive load change. The load resistor's value is changed form $10.67 \mathrm{ohm}$ to $8.89 \mathrm{ohm}$ at $\mathrm{t}=0.4 \mathrm{~s}$ which results in increased current i.e. $37.5 \mathrm{~A}$ to 45A. Fig. 4 shows the response of both PI an FLC based system for the applied resistive load change. It also shows the active and reactive power flow waveforms. 

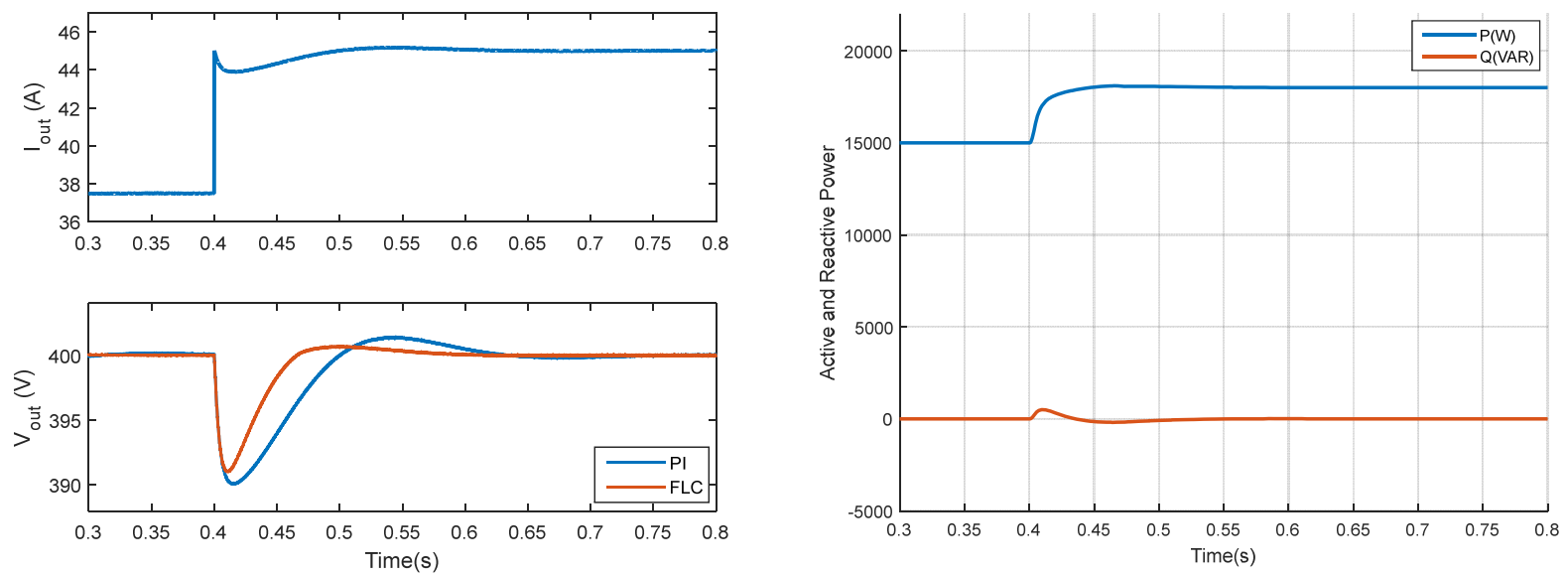

Fig. 4. Output voltage and Power response to resistive load change

Due to the resistive load change the load demand also changes from $15 \mathrm{~kW}$ to $18 \mathrm{~kW}$. The value of zero for reactive power component verifies unity power factor operation. It can be clearly observed that the FLC based system responds much better to the applied change. It has less undershoot and very short settling time. It is evident from the transient response that fuzzy logic controller effectively compensates the overall transient effects and quickly restores the system to steady state condition.

Fig. 5 shows the input voltage and current waveform for one phase of the FLC based system.
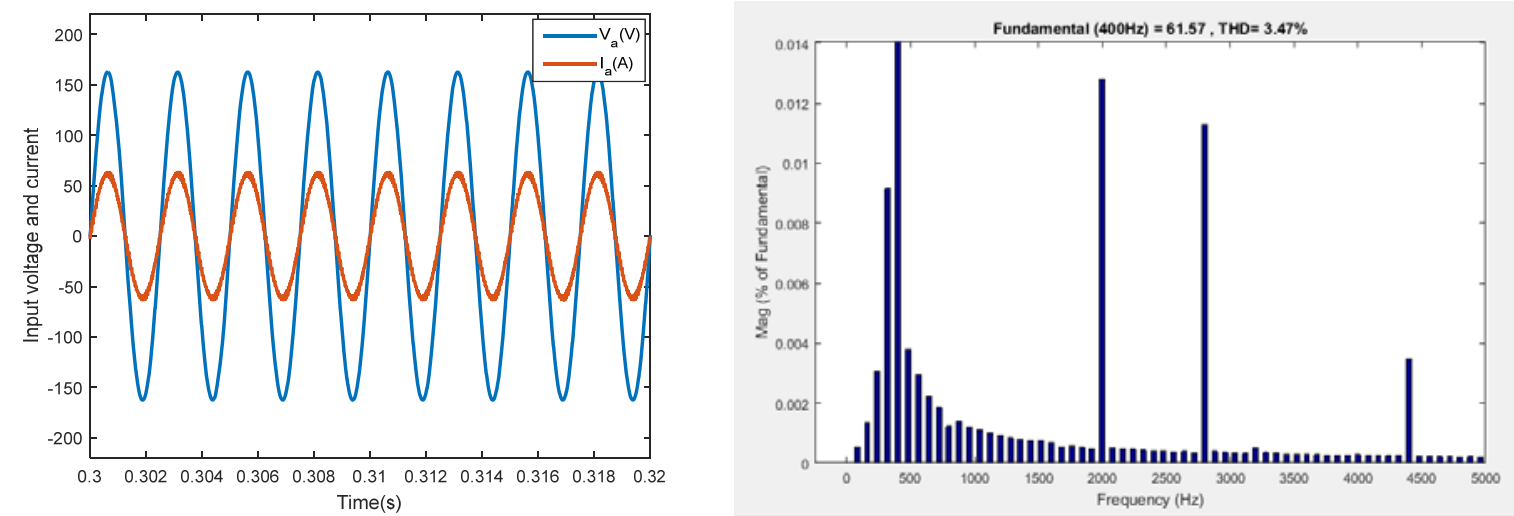

Fig. 5. Power factor and THD analysis

The input current waveform is in phase with the voltage waveform required for the system to have unity power factor. Fig. 5 also shows the harmonic analysis plot of the input current waveform where the fundamental component at $400 \mathrm{~Hz}$ is clearly dominant. The value of THD is computed to be $3.47 \%$. The low value of THD validates the sinusoidal current waveform and is well within the limit of the harmonic standard [9-10].

\section{Conclusion}

This paper discusses the control system for a three phase pulse width modulation AC-DC converter. The conventional PI and a fuzzy logic controllers are designed and implemented in the outer voltage loop. The performance of the system is evaluated for both controllers by applying certain load change. The results show that fuzzy logic based controller is more efficient to regulate the output voltage compared to the PI based controller. The fuzzy logic based system has a sinusoidal waveform for input current which is also in phase with the corresponding phase voltage to ensure a low value of THD and unity power factor. 


\section{References}

[1] K. I. Hwu, and T. J. Peng, "A Novel Buck-Boost Converter Combining KY and Buck Converters", IEEE Transactions on Power Electronics, Vol. 27, No. 5, May 2012.

[2] A. Chaoui, J. P. Gaubert, F. Krim and G. Champenois "PI Controlled Three-phase Shunt Active Power Filter for Power Quality Improvement"- Electric Power Components and Systems, 35:12, pp. 1331-1344, 2007.

[3] A. Semmah, A. Massoum and Patrice Wira "Improvement of PWM Rectifier Performances Using Direct Power Control and Fuzzy Logic Theory", Australian Journal of Basic and Applied Sciences, 7(4): 297-303, 2013.

[4] S. H. Zak, Systems and control: Oxford University Press New York, 2003.

[5] Y Liyong, L.Y inghong, C Yaai and L.Zhengxi, "A Novel Fuzzy Logic Controller for Indirect Vector Control Induction Motor Drive", Proceedings of the IEEE 7th World Congress on Intelligent Control and Automation, Chongqing, China, pp.24-28, June 2008.

[6] J. H. Lilly, Fuzzy control and identification: John Wiley \& Sons, 2011.

[7] D. Q. Dang, Y. S. Choi, H. H. Choi, and J. W. Jung, "Experimental Validation of a Fuzzy Adaptive Voltage Controller for Three-Phase PWM Inverter of a Standalone DG Unit", IEEE Transactions on Industrial Informatics, vol. 11, pp. 632-641, 2015.

[8] K. Tanaka and M. Sugeno, "Stability analysis and design of fuzzy control systems", Fuzzy Sets Syst., vol. 45, pp. 135-156, 1992.3

[9] F. Botterón and H. Pinheiro, "A three-phase UPS that complies with the standard IEC 62040-3", IEEE Transactions on Industrial Electronics, vol. 54, pp. 2120-2136, 2007.

[10] Limits for Harmonic Current Emissions (Equipment Input Current up to and Including 16A Per Phase), IEC 61000-3-2 International Standard, 2000. 